\title{
ASSOCIATION BETWEEN MATERNAL DISEASE DURING PREGNANCY AND MYOPIA IN THE CHILD*
}

\author{
BY
}

\author{
PETER A. GARDINER AND GRIFFITH JAMES \\ London
}

CONGENITAL MYOPIA has been shown to be associated with prematurity (Gregory, 1957; Eames, 1946; Drillien, 1958). These studies did not preclude the possibility that the cause of prematurity might be associated also with myopia in the infant. In the present investigation two series of consecutive cases of congenital myopia have been studied in different districts. The mothers of these children were all asked about the history of their pregnancy and it was also possible to obtain some information about siblings. A control group of mothers and children suffering from visual disorders other than congenital myopia was also asked the same questions. The results are set out in Table I (opposite).

It appears that the "toxaemias" occurred in 50 per cent. of the 38 cases in the myopic group and that in a further 25 per cent. well-defined maternal disease occurred. In this context the term "toxaemia" includes hypertension, pre-eclampsia, and renal disease.

Amongst the mothers whose children had other visual defects only 13 per cent. had had toxaemia and only 25 per cent. were ill compared with 75 per cent. of the mothers of myopes. Another notable contrast is that most of the diseases mentioned by the mothers of myopes had seriously interfered with health during pregnancy, whereas amongst the mothers of children with other eye defects the complaints were mainly trivial.

Prematurity was not a feature in the myopic series of cases. Only five cases were noted as premature, and at least two of these weighed $5 \mathrm{lb}$. at birth. The mean birth weight was $7 \mathrm{lb} .3 \mathrm{oz}$. in the myopic group and $7 \mathrm{lb}$. $6 \mathrm{oz}$. in the other group. The birth distribution in the two groups (Table II, opposite) shows little difference.

In all except one of the myopic cases there appeared to be no other congenital defect. The exception was a mentally retarded child born of a myxoedematous mother.

The myopia was of a high order, being more than $-4 \mathrm{D}$ in all cases. In the fourteen cases where there was information about siblings, only one showed a similar degree of myopia. The rest of the siblings had either

* Received for publication March 18, 1959. 
TABLE I

INCIDENCE OF CONDITIONS OCCURRING IN PREGNANCY AMONGST MOTHERS OF CHILDREN WITH VISUAL DEFECTS

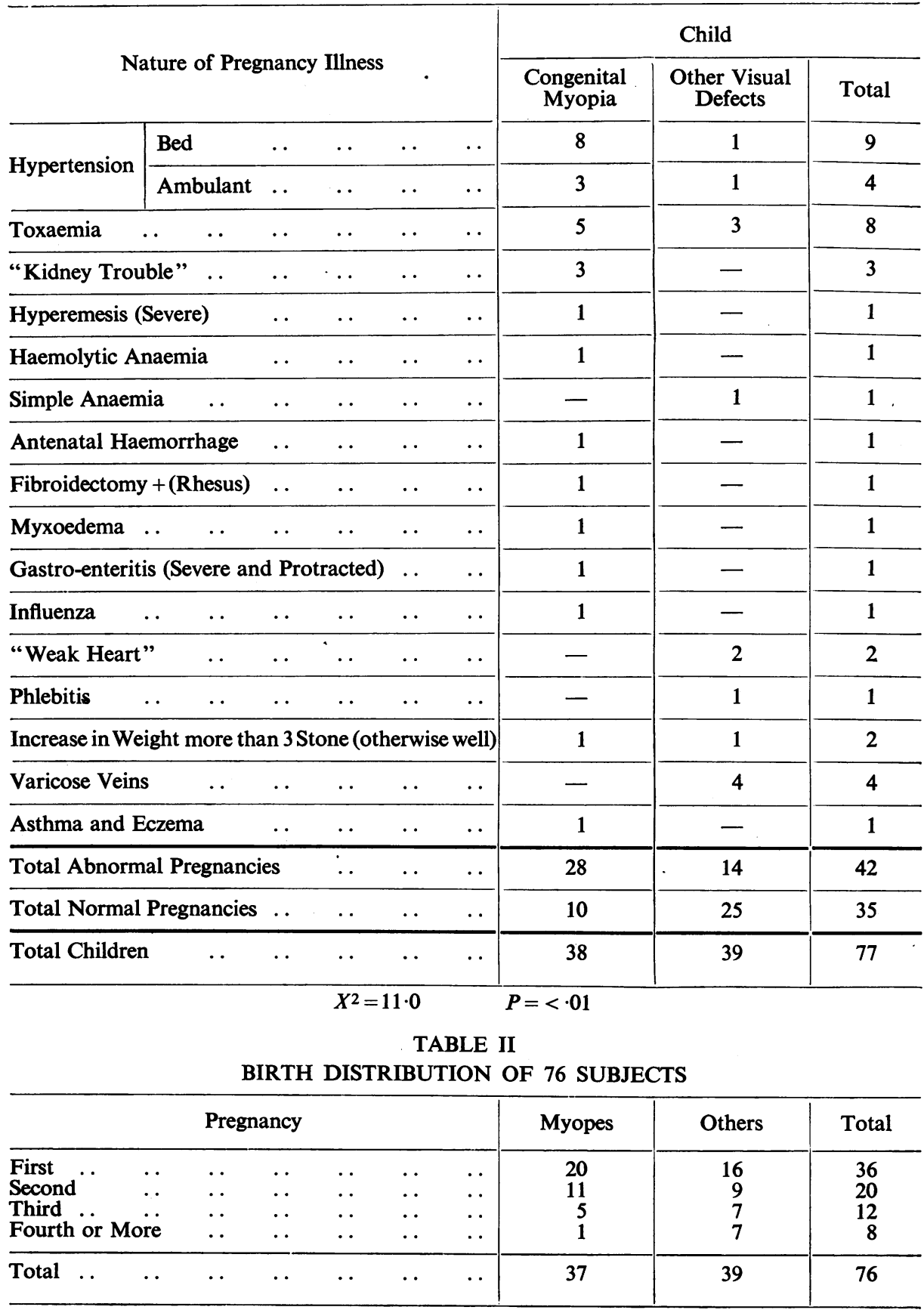


normal or hypermetropic refractions. Five out of the first 25 children had a myopic parent. The remainder were not asked about parental eyesight. Insufficient evidence was obtained to enable us to report on the pregnancy history before the birth of most siblings of the myopes though in five instances a normally-sighted sibling was born after a normal pregnancy to a mother who had had an abnormal pregnancy before her myopic child was born. On the other hand, one mother had kidney trouble in three pregnancies, but only one child was born myopic.

These myopes are probably a representative sample of children with congenital myopia. They would exclude, however, those children who are feeble-minded or already in institutions, and some children who are blind as a result of their myopia. Mongols would not be likely to be seen in this series, as the children were nearly all seen at routine school inspections, and were therefore relatively healthy and uncomplicated cases of congenital myopia. This renders the results obtained all the more striking, as 75 per cent. of the pregnancies were markedly abnormal amongst the mothers of the myopes whereas only 18 per cent. of the other mothers had had marked illness during pregnancy.

\section{Discussion}

There is thus an apparent association between maternal disease and infantile myopia. It would be wise not to stress the physical normality of these cases because mental defects are undoubtedly associated with some cases of infantile myopia. Moreover, although some children showed minor myopic characteristics in their fundi, there were no posterior staphylomata, marked temporal crescents-colobomata-nystagmoid movements, etc. Therefore, myopia exists as the only physical defect in many young children. For this reason it is likely that myopia can develop late in pregnancy. If it occurred only early in pregnancy it would be more frequently associated with other ocular and physical defects. It is known to be present by the 7th month as shown by studies of retrolental fibroplasia (Gregory, 1957). It has also been stated (Fletcher, 1953) that the eye is always myopic in the early stages of pregnancy.

It is the general opinion that congenital myopia rarely alters and its presence in infancy should therefore indicate that the myopia existed at birth.

This fact, in addition to the findings in our series, points to the importance of intrauterine events. Once outside the uterus the myopia does not usually alter until degenerative changes set in in adult life. If these eyes were abnormally "weak" and intrinsically abnormal, one would expect the condition to be progressive from the start. It is probable that these eyes are as likely to change their refraction as a normal child's eye, i.e. only a minority of normal eyes become myopic and only a minority of these 
congenital myopes become more myopic. It follows that a fault of the uterine environment and not one of the eye itself may be a prime cause of congenital myopia.

If it is true that the premature eye is always myopic, then it follows that in our series of cases some change in the later stage of pregnancy has failed to occur in the eye, and that these children are in fact born with "premature" eyes though the rest of the body is fully developed. In retrolental fibroplasia a fluctuating myopia is often found and it may be that some children of toxaemic mothers are born myopic and become emmetropic. This is unlikely owing to the static nature of infantile myopia though marked improvement in an infantile high myope is not unknown to us.

The eyeball lengthens during the last 3 months of pregnancy (Keeney, 1951), and in the present series of cases this is the period when most of the maternal diseases occurred, though some were also present throughout pregnancy. While the eyeball is actively growing it is possible for the process to be disordered during the last months of pregnancy either towards myopia or towards hypermetropia. On the latter point we have no knowledge, and it would require a very much more intensive examination of the integration of eye disease and general medical conditions to enable such an association to be proved.

It may seem peculiar that myopia should be the only physical sign in the new-born infant to be associated with disease during late pregnancy, but this is not really so. For instance, retrolental fibroplasia and blindness was often the only hazard that some premature children had to face once their survival was assured. This is probably because the retinal vessels are still being developed in late pregnancy whereas, as far as is known, the vascular system elsewhere is-if not complete-at any rate being developed from normal and not embryonic vessels. Secondly, acquired myopia, in many cases progressive, occurs in very many otherwise healthy children during growth and adolescence. It is justifiable, therefore, to regard the eye during growth as having a special intrinsic susceptibility to permanent disabling departures from the normal as compared with the body as a whole. Excessive irregularity of growth and some dietary imbalances are however connected with acquired myopia (Gardiner, 1954, 1958), so that the apparent isolation of the eye is one of effect or degree and not necessarily due entirely to some restricted local condition. These growth and dietary studies show that the eye in myopia is taking its own special part in the bodily changes as a whole.

The problem of how much hereditary influences could obscure this association is in our opinion impossible to solve without estimating refractive errors on all the relatives. Personal statements about sight (and loose remarks in lay terms about short sight and long sight) are quite valueless. One of us has seen and been corrected by a man wearing $+8 \mathrm{D}$ sph. who said he was short sighted! In a sense he was right. In six out of the first 25 
from the present series there was no family history whatever of myopia; in five cases one parent was probably myopic; in no case were both parents probably myopic. Without accurate refractions of all relatives it appears that a genetic influence was not a major factor in producing congenital myopia amongst these children. The evidence obtained about siblings in our series, limited though it is, tends to show an association between maternal disease and congenital myopia rather than an association in refraction between children in the same family.

Toxaemia of all sorts is estimated to occur in about 10 per cent. of all pregnancies in the British Isles, but definitions of the term vary. In our control group it was 13 per cent. The term toxaemia here histed includes hypertension, pre-eclampsia, eclampsia, and renal disease. In our myopic series, 50 per cent. of the deliveries-mostly at about full-term-occurred after pregnancies in which these disorders were present. We would, therefore, argue not only that there was an association between congenital myopia and pregnancy toxaemia but also that these cases of myopia are not necessarily associated with prematurity.

In retrolental fibroplasia the essential precondition is an excessive oxygen supply to the new-born. Whether or not this is connected with the associated myopia found by Gregory is highly debatable. The myopia was probably intra-uterine in origin and associated with the condition causing the prematurity though Gregory does not mention the histories of the pregnancies. It is of interest to note that in her series of 30 cases, eight were twins. Our series included two sets of twins out of 38 pregnancies. Twin pregnancy of itself, therefore, is not likely to be a cause of myopia though it is acknowledged to be a cause of prematurity. None of the children in our series showed signs of retrolental fibroplasia and as far as we know none had had oxygen therapy.

If the loss of protein which is common in toxaemias had a decisive part in these infants, one might expect them to be small, but this was not so, their mean birth weight being $7 \mathrm{lb}$. 3oz., only $3 \mathrm{oz}$. less than the others. It could be argued that these myopic children grew to a normal birth weight in spite of the chances of an impaired intra-uterine nutrition. This would tally with the findings in acquired myopia. In older children, myopia is most progressive in those who grow fast and refuse animal protein (Gardiner, 1956). It is probable that there is an imbalance between growth and food factors. This could sometimes be the case in utero, and as it is not likely that protein deficiency is more than one amongst several factors in acquired myopia it would at any rate be consistent to assume the same in cases of congenital myopia. This would fit in with the preponderance of cases of toxaemia occurring in association with protein loss and sometimes slightly lowered serum protein in the mother (Dieckmann, 1952), and would at the same time leave room for alternative causes. It is possibly of some significance that one of our cases suffered from myxoedema, which is known 
to cause not only anaemia but also a 15 per cent. reduction in blood volume (Gibson and Harris, 1939). This reduction in blood volume is also found in pre-eclampsia and eclampsia (Freis and Kenny, 1948) and occurs before the manifestation of other clinical signs which might be of some significance in some so-called normal pregnancies.

Another of our patients suffered from a haemolytic anaemia, again suggesting the possibility that maternal blood factors are important.

Many investigators have shown that the blood calcium in toxaemia is normal. In view of this and in the absence of any proof that calcium per se is implicated in acquired myopia, the role of this food factor is not likely to be of importance.

There are other possible influences: for instance, in toxaemias the placental oestrogen is said to be diminished (Smith and Kennard, 1937) and placental infarctions occur more frequently than in normal pregnancies. Brown and Veale (1953) showed that there was a reduction in the blood flow through the placenta in toxaemia compared with that found in a normal pregnancy.

Walker and Turnbull (1953) also showed that the oxygen saturation in the umbilical vein is less in toxaemia than in normal pregnancy.

There are therefore a number of indications that the foetal environment may not be normal in maternal disease and this accords with some of the factors known to be associated with acquired myopia.

\section{Prevention and Detection of Myopia}

Although congenital myopia is rare and is possibly not the same lesion as acquired myopia, special schools, blind homes, and mental institutions contain a large number of congenital myopes and considerable resources are needed to educate many of these children. These considerations, apart from the distress of blindness and mental defect, are sufficient warrant to explore the possibilities of prophylaxis.

There is need for further research into the connexion between pregnancy disorders and ocular disorders, including refraction errors in general. For example, although it is suitable for the purposes of this paper to use a control group of children with defective eyes, some of these defects, though largely acquired, may have been associated with pregnancy disorders.

Secondly, although in our series of cases prematurity was not a feature, Drillien (1958) reported that, in a series of children with low birth weight, 65 per cent. had a visual defect by the time they were of school age, the commonest being myopia. Out of 43 children, eleven had myopia (six of high degree), but this is probably an underestimate because all children of pre-school age were not examined. As myopia is the commonest cause of blindness in middle-age in England and is a major disability in a high proportion of the population, it appears highly desirable to glean more information on the state of the eyes at pre-school age in ill, disabled, or 
retarded children than is at present the custom. It would help if refractions could be performed on all children taking part in prospective surveys carried out by paediatricians and others under proper statistical control. The actual problem could then be defined even if no solution was found.

\section{Summary and Conclusions}

Congenital myopes are shown to be born far more frequently after pregnancies complicated by serious illnesses than children with other visual defects.

This congenital myopia is not associated with prematurity.

Mothers with "toxaemia" were found four times as frequently as parents of children with myopia than of those with other visual defects.

It is pointed out that congenital myopia may be analogous with acquired myopia, in that the evidence points to its occurrence in a child whose general growth is normal but whose nutrition may be abnormal.

It is suggested that more intensive research should be directed to discovering the association of the development of normal sight, both intra-uterine and post-natal, with other factors which may be surveyed from time to time in growing children.

\section{REFERENCES}

Brown, J., and Veale, N. (1953). J. Obstet. Gynaec. Brit. Emp., 60, 141.

Dieckmann, W. J. (1952). "The Toxemias of Pregnancy", 2nd ed. Mosby, St. Louis.

Drillien, C. M. (1958). Arch. Dis. Childh., 33, 10.

EAMES, T. H. (1946). Amer. J. Ophthal., 29, 57.

FleTCHER, M. C. (1953). J. Pediat., 43, 499.

FrEIS, E. D., and KeNNY, J. F. (1948). J. clin. Invest., 27, 283.

GARDINER, P. A. (1954). Lancet, 1, 476. (1956). Brit. med. J., 2, 699. (1958). Lancet, 1, 1152 .

Gibson, J. G., and HARRIS, A. W. (1939). J. clin. Invest., 18, 59.

GREGORY, I. D. R. (1957). Brit. J. Ophthal., 41, 321.

KeENEY, A. H. (1951). "Chronology of Ophthalmic Development" (Amer. Lect. Series, 99). Thomas, Springfield, Ill.

Smith, G. V., and KenNard, J. H. (1937). Proc. Soc. exp. Biol. (N. Y.), 36, 508.

WALKER, J., and TuRnBull, E. P. N. (1953). Lancet, 2, 312. 